\title{
Assessment of human immediate response capability related to tsunami threats in Indonesia at a sub-national scale
}

\author{
J. Post ${ }^{1}$, S. Wegscheider ${ }^{1}$, M. Mück ${ }^{1}$, K. Zosseder ${ }^{1}$, R. Kiefl ${ }^{1}$, T. Steinmetz ${ }^{1,2}$, and G. Strunz ${ }^{1}$ \\ ${ }^{1}$ German Remote Sensing Data Center (DFD), German Aerospace Center (DLR), 82234 Wessling, Germany \\ ${ }^{2}$ Julius-Maximilians-University Würzburg, Geographic Institute, Am Hubland, 97074 Würzburg, Germany
}

Received: 27 February 2009 - Revised: 18 June 2009 - Accepted: 27 June 2009 - Published: 6 July 2009

\begin{abstract}
Human immediate response is contextualized into different time compartments reflecting the tsunami early warning chain. Based on the different time compartments the available response time and evacuation time is quantified. The latter incorporates accessibility of safe areas determined by a hazard assessment, as well as environmental and demographic impacts on evacuation speed properties assessed using a Cost Distance Weighting GIS approach.

Approximately 4.35 million Indonesians live in tsunami endangered areas on the southern coasts of Sumatra, Java and Bali and have between 20 and 150 min to reach a tsunamisafe area. Most endangered areas feature longer estimatedevacuation times and hence the population possesses a weak immediate response capability leaving them more vulnerable to being directly impacted by a tsunami. At a subnational scale these hotspots were identified and include: the Mentawai islands off the Sumatra coast, various sub-districts on Sumatra and west and east Java. Based on the presented approach a temporal dynamic estimation of casualties and displacements as a function of available response time is obtained for the entire coastal area. As an example, a worst case tsunami scenario for Kuta (Bali) results in casualties of 25000 with an optimal response time (direct evacuation when receiving a tsunami warning) and 120000 for minimal response time (no evacuation). The estimated casualties correspond well to observed/reported values and overall model uncertainty is low with a standard error of $5 \%$.

The results obtained allow for prioritization of intervention measures such as early warning chain, evacuation and contingency planning, awareness and preparedness strategies down to a sub-district level and can be used in tsunami early warning decision support.
\end{abstract}

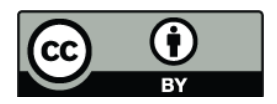

Correspondence to: J. Post (joachim.post@dlr.de)

\section{Introduction}

Especially the 26 December 2004 tsunami clearly revealed the catastrophic consequences when tsunamis are striking areas unexpectedly without early warning or where little or no public awareness of what a tsunami is and how to react to it exists. This event led to strong efforts to design and implement a tsunami early warning system and highlighted the urgent need to strengthen community based disaster management strategies (e.g. awareness raising, preparedness strategies). Central to these issues is a continuous tsunami risk and vulnerability assessment and monitoring which is an indispensable requirement for effective early warning and community level disaster management (UN/ISDR PPEW).

Quantification of human immediate response capability is a key component in tsunami risk and vulnerability analysis. In this context, human immediate response capability refers to people's ability to reach a safe area upon receiving a tsunami warning sign. More generally, human immediate response comprises the reception, processing and decision to take proactive action once tsunami warning signs are present (Mileti, 1995; Drabek, 1999; Sorensen, 1993, 2000; Sorensen et al., 2004; Lindell and Perry, 1992). The ability to reach a safe area depends on intrinsic (sociological and demographic) and extrinsic (environmental settings influencing evacuation speed) factors. In terms of a people-centred tsunami risk assessment the identification of areas where the population possesses weak response capability (difficulties in rescuing themselves and avoiding physical harm) is crucial.

Although substantial research related to the general topic of human response to warnings is available, this is not the case for spatially-distributed quantification of human immediate response capability related to tsunami threats, especially at a sub-national scale. This implies knowledge of indicators describing the theoretical system of human response and availability of data describing these indicators at the respective scale. Especially for factors describing social and

Published by Copernicus Publications on behalf of the European Geosciences Union. 


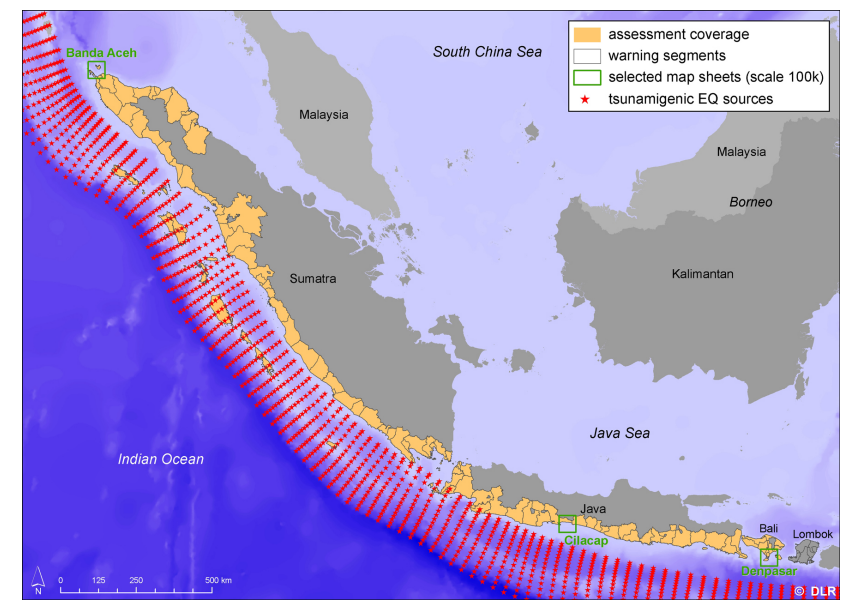

Fig. 1. Overview on presented assessment scale, coverage area of results (in orange), distribution of warning segments along the coast (grey polygons) and tsunami-genic sources (red stars). Areas where exemplary results are shown are highlighted as green boxes.

demographic properties, available data sets are commonly only available through national statistical agencies.

For rapid onset disasters such as tsunami the central factor in quantifying human immediate response capability is time. Knowledge of tsunami warning response properties in the sense of "how much time do people need to rescue themselves?" versus "how much time do they actually have?" is crucial information in the early warning process and disaster management in general.

Consequently, the central aim of this paper is to describe a methodological framework which contextualizes the key components and underlying processes in quantifying human response capability. The following research questions are addressed within this article:

- What are the key determinants describing human immediate response capability related to tsunami threats?

- How can these determinants be framed into a coherent model quantifying response time?

- How can such a model be validated, what is its uncertainty?

- Who might use this information and what is its addedvalue in terms of disaster management?

In answering these questions we focus on a sub-national scale assessment. The target region is the coastal area of Indonesia which can be potentially impacted by tsunamis generated within the Sunda Arc (Fig. 1).

Results and conclusions from the presented work seek to provide key information for tsunami warning decision support, effective warning and warning chain planning, evacuation and contingency planning and for creating awareness in order to foster tsunami adaptation and mitigation strategies.

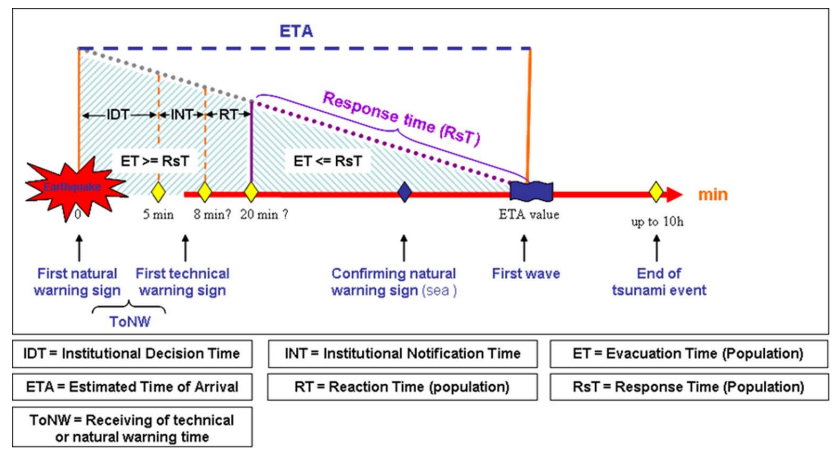

Fig. 2. Assigned time components for the assessment of human response capability to tsunami warning.

\section{Method}

\subsection{Methodological framework}

The assessment unit in quantifying human response capability related to tsunamis is time. The key components determining human response time factors are presented in Fig. 2.

The human response capability depends on the estimated time of arrival (ETA) of a tsunami, the time at which technical or natural warning signs (ToNW, determined by Institutional Decision Time IDT and Notification Time INT, see Fig. 2) can be received by the population, the reaction time (RT) of the population and the evacuation time (ET). The actual available response time (RsT) is then obtained by:

$\mathrm{RsT}=\mathrm{ETA}-\mathrm{ToNW}-\mathrm{RT}$

with

$\mathrm{ToNW}=\mathrm{IDT}+\mathrm{INT}$

Human response capability can then be estimated on the basis of the relationship between ET and RsT. For RsT $>=E T$ people in the respective areas are able to rescue themselves by reaching a safe area. Critical areas possess $\mathrm{RsT}<=\mathrm{ET}$ values because people within these areas will be directly impacted by a tsunami.

As previously mentioned the human response capability is determined by social vulnerability factors which play a role in constituting the reaction time (RT, see Fig. 2). Human reaction time to a tsunami warning depends mainly on warning dissemination (is it received and understood?) and on the response (do people respond by evacuating?). Quantification of these factors needs to consider complex social and psychological settings and processes which consider the sequential process of hearing, understanding, believing, personalizing, confirming and responding to a warning (Sorensen, 2000). Additional challenges lie in describing these processes by relying only on available nationwide statistical data. Birkmann et al. (2009) describe which social parameters represent these 
process factors and the statistical proxies derived to describe social vulnerability in the warning context.

Human response capability depends largely on the extent of the potential tsunami impact on land. This is required to describe the evacuation area or the credible emergency planning zone (EPZ, Cova and Church, 1997). The credible EPZ determines the questions of 'who needs to evacuate and needs special attention', and "where people need to be routed to reach safety". Distribution of warning dissemination devices (e.g. sirens) within the EPZ and institutional settings in disaster management (e.g. availability of standard operational procedures related to warning response/evacuation behaviour) drive the determination of the "Institutional Notification Time (INT)". Finally the response time (RT, see Fig. 2) has to be quantified and accordingly the response capability.

\subsection{Quantification steps}

Central to the assessment of human immediate response capabilities related to tsunamis is the quantification of the respective time components described above. The following quantification steps have to be conducted: (1) Hazard assessment (definition of credible EPZ), (2) Quantification of ETA, (3) Quantification of ToNW and RT, (4) Quantification of ET and (6) Quantification of RsT.

\subsubsection{Hazard assessment}

The first step is to determine the potentially impacted areas on land considering a pre-calculated set of potential tsunamis originating from sources along the Sunda Arc. The determination of the hazard impact area is linked to tsunami warning levels defined within the national Indonesian Tsunami Early Warning Center in order to operationally use human response capability estimation in an early warning context (Post et al., 2008b). Thus, hazard impact zones related to wave height at the coast result in different warning levels (e.g. wave height between 1 and $3 \mathrm{~m}$ at the coast leads to a warning, wave height $>3 \mathrm{~m}$ leads to a major warning). The database for this approach consists of tsunami modelling results provided by AWI (Alfred Wegener Institute, Bremen, Germany) in the context of the GITEWS (German-Indonesian Tsunami Early Warning) project. The model area covers the south coast of Sumatera, Java and Bali.

A database query classifying the modelled tsunami scenarios according to their wave heights at the coast is conducted to derive the respective tsunami hazard impact zones. After the database query follows a calculation of the amount of tsunami impact hits on land in each of the two classes. The area described by all points with hits defines the inundation area depending on the specific warning level (see Fig. 3). Displaying both of the two hazard zones by appending the hazard zone of the "Warning Level" with the hazard zone of

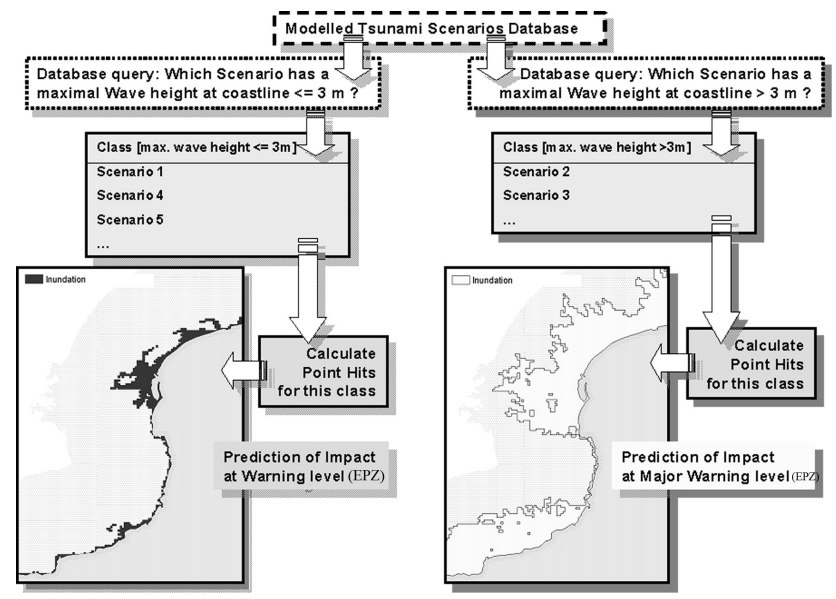

Fig. 3. Workflow to determine credible emergency planning zones (EPZ) based on a multi-scenario approach. Credible EPZs are assigned according to tsunami warning levels (defined by the national warning centre) according to wave height at the coast: $<=3 \mathrm{~m}$ (left side) and wave height at coast $>3 \mathrm{~m}$ (right side). The tsunami scenario data base is provided by the Alfred Wegener Institute, Bremen, Germany (AWI) in the context of the GITEWS (GermanIndonesian Tsunami Early Warning) project.

the "Major Warning Level" finalizes the hazard impact area and hence the determination of the respective credible EPZs.

\subsubsection{Quantification of ETA}

One parameter in the tsunami scenario database is the estimated minimum time of arrival of the tsunami (ETA) per scenario and for predefined coastal locations. Quantification of representative ETA is based on a set of 761 tsunami scenarios covering the range of potentially possible tsunami events along 200 distributed tsunami sources zones (along the Sunda Arc) provided by the German Research Centre for Geosciences (GFZ Potsdam) within the GITEWS project. For each coastal location the median value (50th percentile of ETA distribution at the respective location) is calculated. The values of the coastal locations are then aggregated on warning segments using again the median value of the obtained distribution. Warning segments are pre-defined spatial entities within the Tsunami Early Warning Centre (see Fig. 1) related to district (Kota/Kabupaten) administrative boundaries in Indonesia. For this spatial unit the median ETA is used as representative value for anticipated time of arrival of a tsunami.

\subsubsection{Quantification of ToNW and RT}

In principal human response can be based on natural or technical warning signs. The first requires a sound understanding and knowledge of tsunami warning signs (e.g. earthquake, sudden drop of sea level) and the knowledge of what to do (e.g. evacuate) by the population. It is almost impossible to 


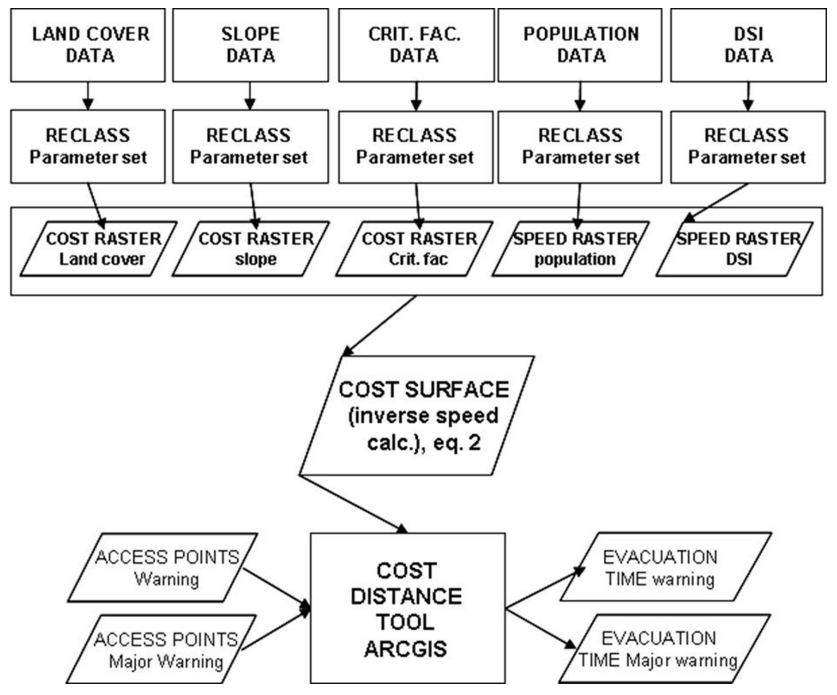

Fig. 4. Workflow to calculate evacuation time (ET) based on key determinants assigned parameterisations (see Table 1) and a cost distance weighting approach.

quantify the time when a natural warning sign could be received at a certain coastal location, although values of a sudden sea level retreat of approx. 5-10 min before the tsunami hits the coast can be assumed. Within this analysis we consider only reliable technical warnings generated and assume it was issued $5 \mathrm{~min}$ after the tsunamigenic event happened, as defined by a decree issued by the Indonesian president. Hence the Institutional Decision Time (IDT) is set to $5 \mathrm{~min}$. An Institutional Notification Time (INT, technical notification time to the warning dissemination devices at the community level) of $3 \mathrm{~min}$ is adopted for this study. Accordingly we assign $8 \mathrm{~min}$ for the ToNW time. This is seen to represent the optimum time duration for detecting a tsunami, inferring expected tsunami properties along the coastal areas and disseminating the warning to devices within local communities. Hence an optimal function of the warning sender is assumed with the optimal sender characteristics laid down by e.g. Drabek, 1999; Mileti and Sorensen, 1990; Sorensen, 2000.

The next unknown is the reaction time (RT), and hence warning receiver characteristics. Theoretically, RT can take time values between zero and the time of the tsunami arrival (ETA). As concluded by Birkmann et al. (2009) a quantitative assessment of RT through indicator sets based on available national statistical data is too uncertain and consequently does currently not allow a further specification of RT in narrowing its theoretical dimension. Additional in-situ information (generated through household surveys and participatory approaches) to determine representative indicators is needed to describe the complex social and psychological settings influencing human reaction times. Considering these current constraints we assume the theoretically possible value range, with an optimum of zero minutes (meaning direct response after receiving a tsunami warning) to the median estimated time of tsunami arrival (ETA median, no response after receiving a tsunami warning).

\subsubsection{Quantification of ET}

The ability to respond properly to a tsunami warning message, i.e. evacuate on time, depends on (1) location of tsunami safe areas and their properties, (2) land cover, (3) topography (slope), (4) population density, (5) age and gender distribution and (6) density of critical facilities (primary schools, hospitals).

The location of safe areas determines the distance an evacuee has to cover. Land cover and slope alters the evacuee's movement and speed (ADPC, 2007). Related to demographic factors it has been found in several studies (e.g. Guha-Sapir and Below , 2006; MacDonald, 2005; Oxfam, 2005; Rofi et al., 2006; Birkmann et al., 2007) that age and gender distributions significantly impact fatality rates due to contributions to longer evacuation times. In evacuation modelling studies, the impact of population density and evacuation properties of different group sizes are accounted for (Klüpfel, 2005; Rogsch, 2005). The larger the group and the higher the population density the slower the evacuation process (Klüpfel, 2003). The existence of critical facilities such as schools and hospitals result in reduced response capabilities due to the presence of people needing special attention during an evacuation (Johnson, 2006). Obviously physical and mental disabilities are limiting factors for individuals to cope during a disaster.

The basic principle is a GIS analysis to define the fastest path (best evacuation route) from a given point to the safe area. Using the determined credible EPZ (both "warning" and "major warning" cases), so called access points to safe areas can be assigned (see Fig. 5). First characteristics of a safe area referred as temporary shelter areas for evacuation are determined. The temporary shelter areas have to be outside the EPZ and have to feature a suitable land use/cover and topography (slope) beside a minimum area of $10000 \mathrm{~m}^{2}$ ensuring sufficient space for temporarily gathering of evacuees.

A measure of travel costs is used which can be considered as travel time (evacuation time) needed when approaching the next safe area. In this concept, the accessibility to a safe area is calculated on a cost surface which consists of a regular two-dimensional grid where each cell value represents the cost to travel through it depending on costs introduced by land cover, population density, slope, critical facility density, age and gender distribution (Fig. 4). The cost is calculated based on Eq. (2). Hence the cost surface represents an inverse speed raster determining the time needed for travelling through a particular path depending on the spatial raster resolution and distance). 
Table 1. Parameterisation used in quantification of evacuation time and parameter input variation used within the uncertainty assessment.

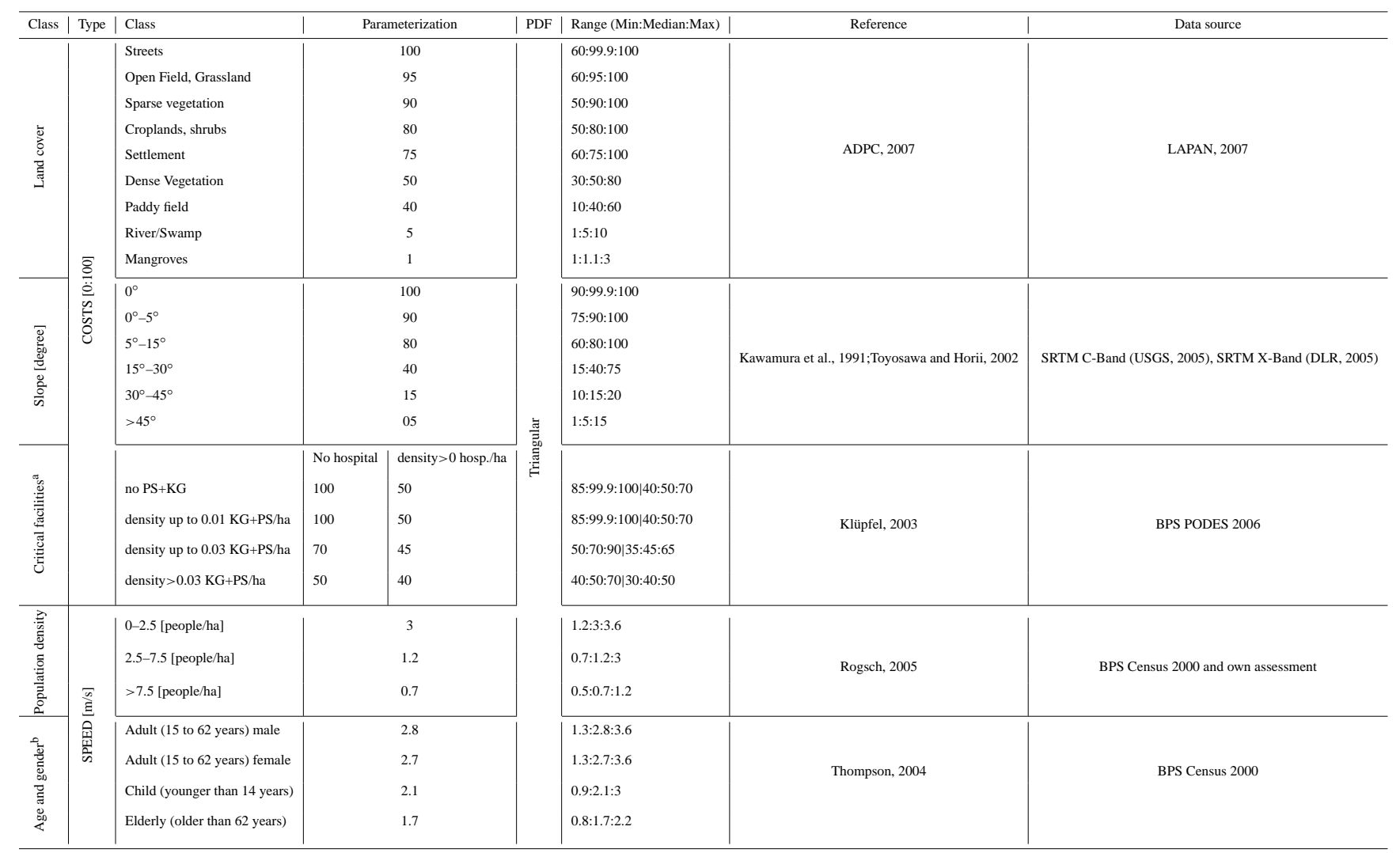

a PS=Primary school, KG=Kindergarten.

b Average speed per desa/village is obtained by: (Number of children (female and male) $\times$ speed + Number of adult males $\times$ speed + Number of adult females $\times$ speed + Number of elderly (female and male) $\times$ speed)/Number of total population.

$$
\begin{aligned}
& \text { inverse_speed }\left[\frac{\mathrm{s}}{\mathrm{m}}\right]= \\
& \frac{1}{\frac{\text { costs_landuse }}{100} \times \frac{\text { costs_lope }}{100} \times \frac{\text { cos ts_criticalfacilities }}{100} \times\left(\frac{\text { speed }_{\text {populationdensity }}+\text { speed }_{\text {age,gender }}}{2}\right)}
\end{aligned}
$$

Using the cost weighted distance approach (ESRI, 2001) the time needed from each location (raster cell) within the credible EPZs to the next safe area (next access point, Fig. 4) is calculated using the ArcGIS cost distance algorithm (ESRI, 2001).

Table 1 provides the parameter values used and relevant literature references. It should be noted that for some parameters empirical studies are not sufficient or not available and own estimates had to be incorporated.

\subsubsection{Quantification of RsT}

RsT is not a static value since some determinants can not be quantified or defined precisely (e.g. RT). As a starting point an optimal (best possible) RsT is quantified by assuming a theoretically ideal warning chain mechanism (opti- mum values for IDT, INT, and RT). The optimum RsT with ToNW=8 $\mathrm{min}$ and $\mathrm{RT}=0 \mathrm{~min}$, can be described as follows:

RsT_opt $=$ ETA $_{\text {median }}-8$

The pessimistic RsT with ToNW+RT $=\mathrm{ETA}_{\text {median }}$ values as follows:

$\mathrm{RsT}_{\text {_pess }}=\mathrm{ETA}_{\text {median }}-\mathrm{ETA}_{\text {median }}=0$

The latter leads to the result that no response time is available. In this case all people located within the credible EPZ are expected to become casualties.

\subsection{Estimation of casualties, displaced people and de- gree of response capability}

Assuming optimal conditions (ref. Eq. 3) a qualitative assignment (degree) of human response capabilities related to a tsunami threat can be derived from:

ET $>=$ RsT_opt $=$ weak response capability

$0.5 \times$ RsT_optandET $<$ RsT_opt $=$ moderate response capability

ET $>=0.5 \times$ RsT_opt $=$ good response capability 
As RsT is not a static value a temporally dynamic representation of response capability has to be found using a calculation which considers an approximation of [ToNW+RT] from 8 minutes up to the respective ETA $_{\text {median }}$ time value per warning segment. For each time interval, $I$, of $5 \mathrm{~min}$ the following relationships are calculated

IF ET $<$ RsT_opt $+I=$ good response capability, for

$I=8$ min toETA median $_{\text {}}$

IF ET $>$ RsT_opt $+I=$ weak response capability, for

$I=8$ min toETA ${ }_{\text {median }}$

It is now possible to determine the respective areas featuring weak, moderate and good response capabilities for each time interval $I$. It is further assumed that people located within a weak response area will not be able to reach a safe area in time and will become a casualty of a tsunami. People being located within a good response area will potentially be able to reach a safe area in time but are then displaced by a tsunami. Casualties and the number of people being displaced can be dynamically calculated assuming the time slices defined by the interval $I$.

\subsection{Plausibility check and uncertainty}

Data on reported dead/missing at the district (Kabupaten/Kota) level for impacted areas in Aceh for the 2004 event were compared to calculated values of casualties to check the plausibility of the overall approach. Thereby it was assumed that no technical warning was received and natural warning signs (retreat of sea level) occurred 5-15 min before the first tsunami wave hit the coast (potential first sign leading to a response/evacuation). We then compare the calculated number of people for response times (RsT) of 5 and $15 \mathrm{~min}$ to the reported values in literature.

Because certain parameters lack a sufficient empirical basis (see Sect. 2.2.4), we performed an uncertainty assessment in addition to a plausibility check. Monte Carlo based global sensitivity and uncertainty analysis using a latin hypercube stratified sampling technique was applied (Janssen et al., 1994; Saltelli et al., 2004; Tarantola, 2001; Post et al., 2008a). The analysis uses multiple evaluations with randomly selected model input and considers the entire range of input factors and their possible interactions with respect to the model output. The Monte Carlo analysis done consisted of the following steps (Saltelli et al., 2004): (1) definition of model variables (input factors) $\mathrm{Xi}$ used for the analysis, (2) selection of ranges and the Probability Distribution Functions (PDF) for each $\mathrm{Xi}$, (3) generation of samples within the PDF's (sampling), (4) evaluation of the model output for each element of the input factor sample and (5) uncertainty analysis. For the assessment of uncertainty the software tool Simlab (Version 2.2, Saltelli et al., 2004; Tarantola, 2001) developed by the Joint Research Centre (JRC) in Ispra (Italy) has been used. For the uncertainty assessment the coefficient of variation (deviation of a variable from its mean, "standard error", COV in \%) was calculated as in Eq. (9) to quantify the uncertainty of the mean value, where $n=$ number of simulation runs, $x=$ mean value of output, $x i=$ output value, $s d=$ standard deviation:

$\operatorname{COV}[\%]=\frac{1}{n-1} \sum_{i=1}^{n}\|(\bar{x}-x i)\| \times \frac{100}{\bar{x}}=s d \times \frac{100}{\bar{x}}$

Uncertainty was assessed based on 250 model runs in order to assure stability of model output variance (Verbeeck et al., 2006). Due to computational constraints the uncertainty assessment was performed for a sub-set of the entire study area (see Fig. 1). The sub-set is a region in central Java featuring representative distributions of input data (land cover, topography, population density, age and gender distribution and density of critical facilities). The parameterization for the uncertainty analysis can be found in Table 1.

\section{Results and discussion}

\subsection{Hazard assessment and quantification of ETA}

The envelope of all inundated locations on land (inundated with a flow depth of at least $0.1 \mathrm{~m}$ ) given for two tsunami intensity classes (warning and major warning level) were mapped out. This represents for each class the worst-case tsunami impact area considering all potential tsunami events (multi-scenario approach). Hence a single event of a certain warning level will inundate only parts of the assigned area and not necessarily the entire area. The extents of respective hazard impact areas for selected areas are given in Fig. 5.

The respective credible EPZ was defined by using the hazard impact area for "warning" and "major warning" tsunami intensity. Relating credible EPZ to hazard impact cases which are further related to warning levels offers the opportunity to link early warning information to response planning at the community level.

Altogether around 4354000 people are living in a tsunami endangered area of approx. $8173 \mathrm{~km}^{2}$ (major warning level tsunami threats originating from the Sunda Arc). This area represents $1.35 \%$ of the land mass of Sumatra, Java and Bali and $2.5 \%$ of overall population. For the EZP representing warning level tsunami threat altogether approx. 193000 people within an endangered area of $642 \mathrm{~km}^{2}$ are exposed representing $0.11 \%$ of people and land area (Sumatra, Java and Bali).

Median ETA values along the coastline vary between 20 and $150 \mathrm{~min}$. This extremely short time window for human response coupled with the population density points 
out the need of an effective early warning system and response structures (e.g. evacuation planning). The question then arises: how much time the people need to reach a safe area?

\subsection{Quantification of ET}

The next step in quantifying human response capabilities related to a tsunami threat is the calculation of the evacuation time (ET). Figure 5 provides ET results for selected areas along the coast (see Fig. 1) in minutes. It is visualized in time slices of $15 \mathrm{~min}$ from 0 to more than $60 \mathrm{~min}$ and for both hazard impact areas (major warning and warning level).

Areas featuring large ET values are distributed along the coastline and inland where no suitable safe areas for a temporary shelter can be found. The analysis considers only an evacuation towards and into a safe area possessing defined properties allowing a temporary gathering of evacuees. Hotspot areas with large ET can be clearly identified. For the major warning case (see Fig. 5 left) large areas with ET values greater than $30 \mathrm{~min}$ point to the apparent need of special attention, sound evacuation planning and good warning dissemination structures in these areas. For the warning case (see Fig. 5 right) ET values are smaller and generally below 30 min. In relation to median ETA values between 20 and $150 \mathrm{~min}$, the estimated evacuation times seem to be sufficient. Consequently under effective warning and evacuation structures most areas feature the potential for being evacuated with low numbers of people being potentially unable to reach a safe area in time.

\subsection{Estimation of casualties, displaced people and degree of response capability}

The quantification of RsT and ET are the key components in estimating the number of casualties, displaced people and the degree of response capability. Major unknown in quantifying RsT is the humen reaction time (RT). As stated in literature, human reaction to a warning is a complex social process whereas major determinants are documented in literature, also for tsunami related disasters (Charnkol and Tanaboriboon, 2006; Mileti and Sorensen, 1990; Sorensen, 2000). Warning receiver properties as e.g. tsunami disaster experience, knowledge, household size, social networks, access to warning, educational level and warning sender properties as e.g. credibility, warning certainty and frequency playing key roles in human reaction are known. Although relying on nationwide available statistical data adds the challenge to find statistical proxies representing key indicators of sender and receiver properties (Birkmann et al., 2009). Warning dissemination and warning decision proxies were found and aggregated to the proxy "access to information and knowledge" qualitatively describing population's reaction time (high, medium, low (Birkmann et al., 2009). But translating a qualitative assessment to quantification in terms

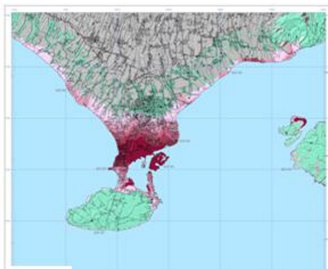

a)

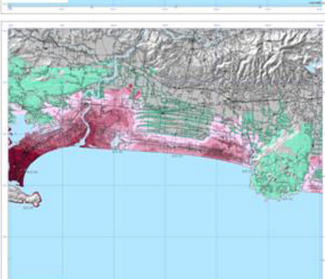

c)

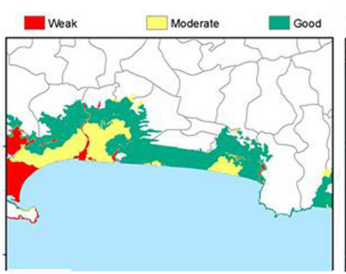

e)

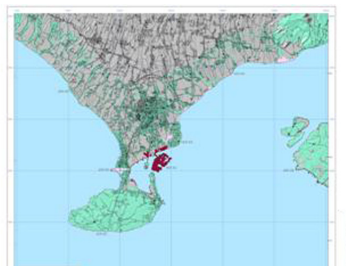

b)
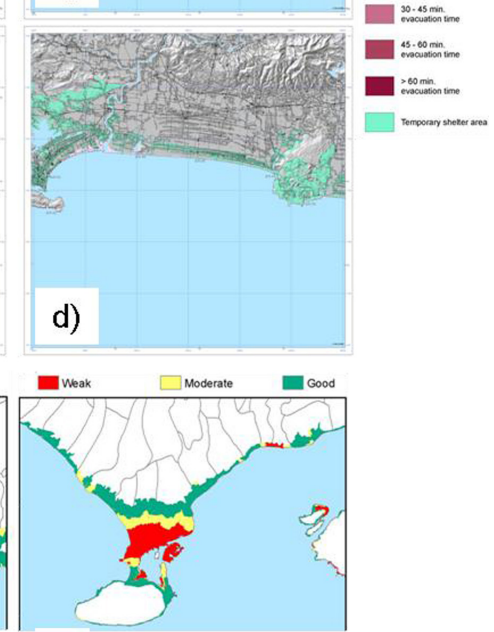

f)
Fig. 5. Examples for Denpasar (Bali, a and b) and Cilacap (Java, c and d), Indonesia for quantified evacuation times (ET) based on major warning tsunami (left column) and warning tsunami impact area (right column) visualized as 15 min time classes. Designated safe areas for evacuation are depicted in green. Light pink to dark purple areas constitute credible emergency planning zones (derived from hazard assessment). (e) and (f) show classifications of weak, moderate and good response capability for Cilacap (e) and Denpasar (Bali, f).

of reaction times is highly uncertain, as sub-national proxies need validation based on participatory approaches and household surveys at the local level to derive more robust indicators to describe social response processes. Adding a validation to the sub-national proxy would then allow an assignment of approximate reaction times. Recent findings by (Charnkol and Tanaboriboon, 2006) suggest reaction times depending on available response times (in our case estimated ETA). Based on household surveys for selected regions in Thailand impacted by the tsunami 2004 they found for certain response times (RsT) of 60, 45, 30 and 15 min respective reaction times of 15 to 30,13 to 25,10 to 20 and 5 to $10 \mathrm{~min}$. Using these findings an estimation of reaction times based on the estimated time of tsunami arrival (ETA) seems possible but needs further research efforts currently conducted. For the moment we assumed a direct reaction after the receiving of a warning and consequently an optimal human reaction time, optimal institutional (Tsunami Warning Center) decision and notification time. Following that, the response 


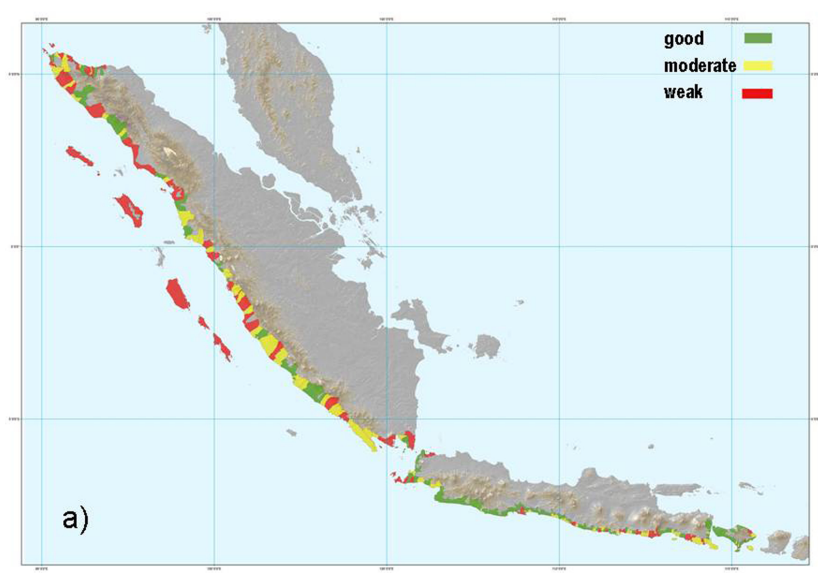

Fig. 6. Sub-national scale representation of human response capability categorized as good, moderate and weak. The represented area is aggregated on a Kecamatan (sub-district) administrative level. Human response capabilities are based on optimal reaction and institutional notification and decision times and hence e.g. red areas generally posses a weak response capability even if people take immediate action and were notified 8 min after a tsunami-genic event.

time RsT is mainly constrained by the calculated median estimated time of arrival per warning segment along the coast.

According to Eq. (5), the response capability was classified as good, moderate and weak in order to obtain a general picture and qualitative interpretation of human immediate response capability related to tsunami threats. Difficult-toevacuate areas can be identified as red zones (Fig. 5) where the estimated time to reach a safe area is longer than the optimum response time. Consequently, people located within the red zone are likely to become casualties.

Large areas featuring weak response capabilities were identified in the study area (see Fig. 6). Prioritization of intervention measures, such as evacuation planning, increasing warning dissemination devices and awareness raising, within these areas can be implemented. By visualizing the immediate response capability on the sub-national scale (information aggregated on Kecamatan/sub-district level) regions facing severe problems can be identified. The Mentawai islands off the Sumatra coast and various sub-districts in Sumatra can be especially noted in Fig. 6. In Java, especially the south-western coast, good response capabilities for successful evacuation are shown. Although it has to be considered that this qualitative assignment is based on optimal response time conditions (from Eq. 5) and assumes an immediate human reaction to evacuate as well as effective early warning.

According to Eqs. 6 and 7 the difficult-to-evacuate area (the weak response capability class) can be determined for different time steps until the ETA $_{\text {median }}$ is reached. Areas falling in the "weak response capability" class were determined for time steps of 5 minutes from RsTopt to RsT=0 min.
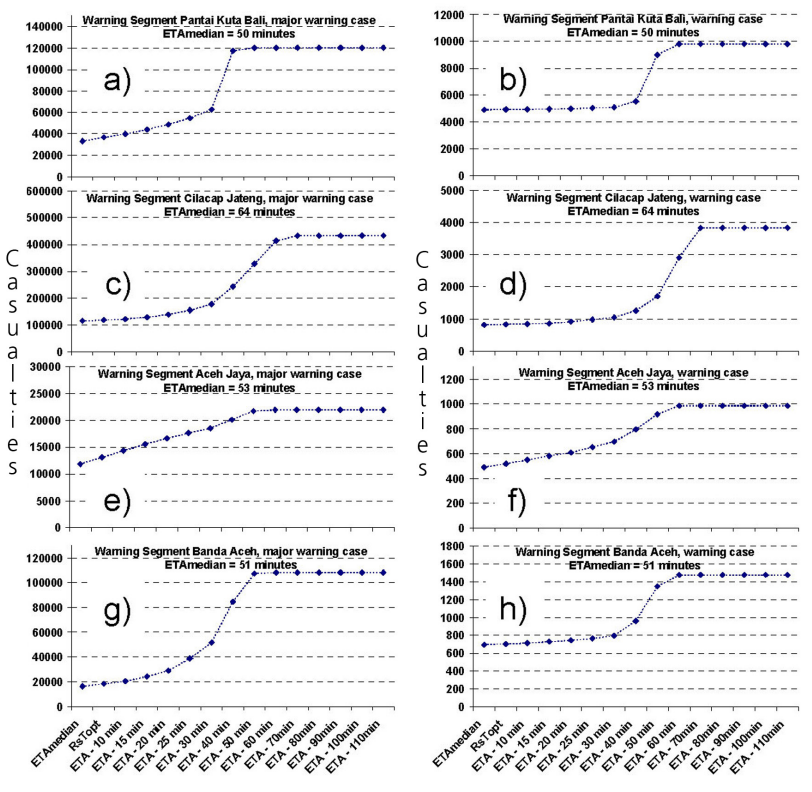

Fig. 7. Number of casualties as a function of response time and median ETA values for warning segments Pantai Kuta Bali (a, b), Cilacap Jateng (c, d), Aceh Jaya (e, f) and Banda Aceh $(\mathbf{g}, \mathbf{h})$ and considering major warning impact zone (left) and warning impact zone (right).

For each time step the amount of people distributed in the weak response capability area was quantified. This was done for each warning segment and credible EPZ (warning and major warning level).

Figure 7 illustrates the casualties for selected warning segments, as a function of available RsT. At RsT $=0$ all people within the credible EPZ are directly impacted.

Generally the curves in Fig. 7 feature small increases followed by a rapid increase in casualties at a certain time and then approaching the number of people exposed (amount of people within a credible EPZ). For the case of warning level the relatively slow increase of casualties in the first 10 $15 \mathrm{~min}$ is more pronounced than for the major warning case. As expected, the longer the response times the fewer casualties. Only an effective early warning system together with knowledge on the correct interpretation of natural warning signs can improve the response time. Without these conditions and with only a short response time casualties are a multiple. The result for Kuta (Bali, Fig. 7b) for a major warning case results in approx. 25000 casualties for RsTopt (direct evacuation when receiving a tsunami warning sign) to 120000 for $\mathrm{RsT}=0 \mathrm{~min}$ (no evacuation action until tsunami hits the land). Wang and Lian (2008) support these findings by stating that effective early warning (optimizing response time) can reduce casualties by more than half.

The number of casualties depending on response time intervals also highlights the importance of human reaction capabilities. Charnkol and Tanaboriboon (2006) found human 
reaction times related to tsunami disasters between 5 and $35 \mathrm{~min}$. Slow reaction times lead to extremely high numbers of casualties. This can be mitigated by increasing people's perception of risk and educating on appropriate evacuation behaviours.

\subsection{Plausibility check and uncertainty}

A direct verification or validation of the presented approach above is not possible. This is mainly due to the fact that we can only compare calculated casualties considering the two hazard impact zones (warning and major warning levels). Consequently the spatial extent of the hazard impact zone aggregated from many tsunami scenarios at the major warning level is not identical to a single event falling into the major warning class. However a comparison with available reported event data (on casualties and dislocated people) to estimated values is important to check for plausibility and robustness.

For this reported data concerning the Aceh 2004 event (JICA, 2005; Doocy et al., 2007) was used and compared them to the calculated estimations of casualties. We assumed that for this case RsT was around 5 to $15 \mathrm{~min}$, as no early warning was in place and people were unprepared (RT was very long). The following figure gives a comparison of reported dead/missing (JICA, 2005) to the estimated number of casualties.

As can be seen in Fig. 8, the estimated number of casualties corresponds well to reported dead or missing in literature. For the Kabupaten (district) Aceh Jaya estimated casualties (18500 and 20000) are compared to 19660 reported (Fig. 9, top). For Kota Banda Aceh estimated values are between 52000 and 85000 ( 5 and 15 min before tsunami hit the coast) stand against 78500 reported (Fig. 9, bottom). This simple comparison demonstrates that magnitudes of estimated numbers are plausible and robust.

Input data variation (see Table 1) induced an absolute uncertainty range between 103.3 and 189.16 minutes (5th and 95th percentile values of ET distribution based on 250 model runs). A coefficient of variation ("standard error") of $4.93 \%$ on the model output was calculated. Hence a variation of $\sim 5 \%$ around the mean value is present due to variation of input parameters. That means that for an evacuation time of e.g. $60 \mathrm{~min}$ an uncertainty of $+/-3 \mathrm{~min}$ has to be taken into consideration.

Spatial distribution of model uncertainty based on COV values can be seen in Fig. 9. Low COV values are present along the coast and increase further inland. The increase in uncertainty towards tsunami safe areas is mainly due to the spatial configuration of access points. The number and distribution of access points significantly affects the quantification of ET (more access points lead to improved accessibility of safe areas and hence shorter distances and lesser ET). Another source of uncertainty is numerical tsunami modelling relying on correct representation of onshore hydrodynamics. a) Kab. Aceh Jaya

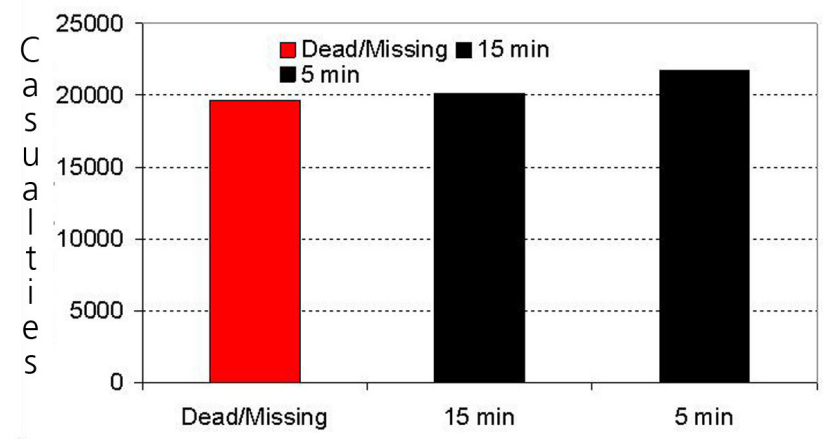

b) Kota Banda Aceh

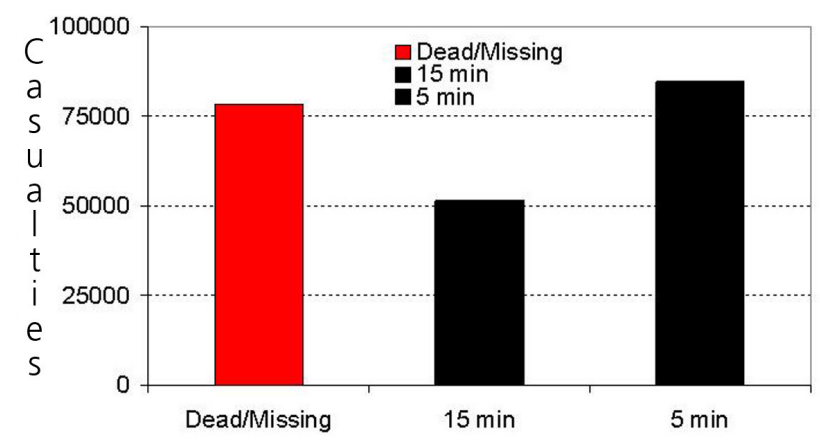

Fig. 8. Comparison of reported dead or missing after the Aceh 2004 tsunami event (red bar, JICA, 2005) to estimated values of casualties for 5 and 15 min response times (black bars) for Kabupaten (District) Aceh Jaya (a) and Kota (District) Banda Aceh. Please note that estimated values are based on major warning level tsunami impact area which is not identical to inundation extent of the Aceh 2004 tsunami in the respective regions.

Here representation of land cover roughness, input data spatial resolution (topography and bathymetry) introduces uncertainties which propagate to the quantification of the hazard impact zone (credible emergency planning zone and location of safe places). Overall COV values are relatively low within high risk areas (areas along the coastline). Hence ET quantification features a low uncertainty in areas where robust information is necessary for decision makers.

The relatively low uncertainty and plausible comparison of estimated to reported values hint to a robust system description of human response capabilities considering key determinants and their parameterisation within the assessment framework. Although the estimated amount of casualties provides solely the order of magnitude and of course not any precise quantification. 


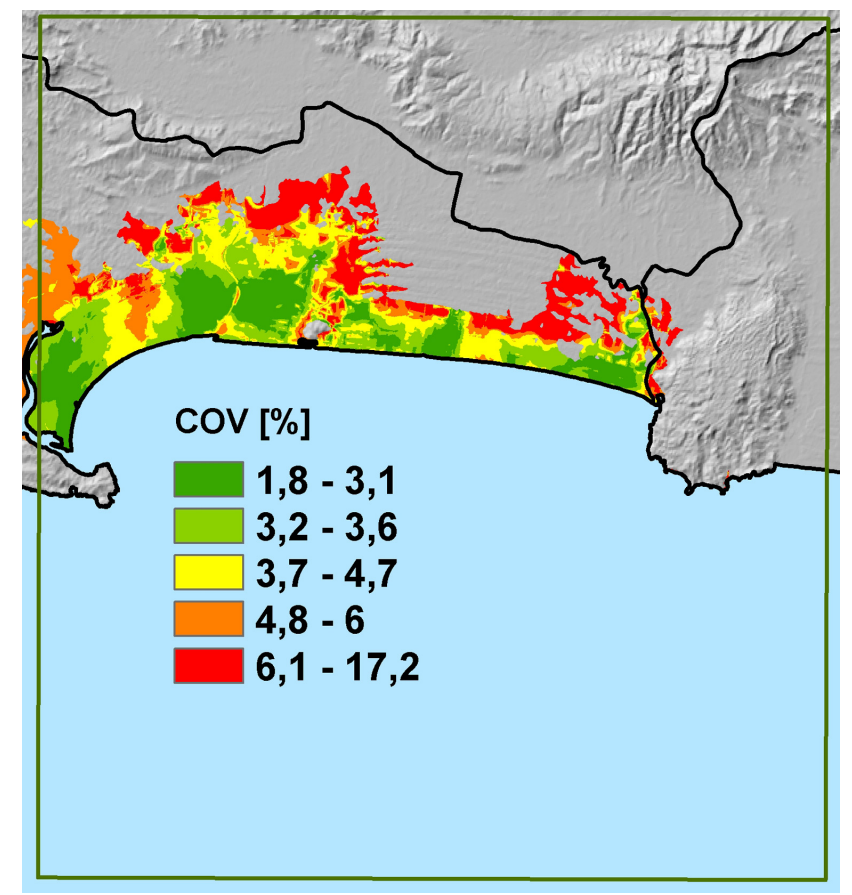

Fig. 9. Spatial distribution of uncertainty considering the percentage coefficient of variation (COV, "standard error") for a representative sub-set of the study area (region Cilacap, Java see Fig. 1).

\section{Conclusions}

A methodology to estimate human immediate response capability related to tsunamis at the sub-national scale for Indonesia (specifically, coastal areas of Sumatra, Java and Bali facing the Sunda Arc) is presented. Conceptually, human immediate response capability is assessed by estimating the time people potentially need to rescue themselves (ET) and the time people actually have (RsT). ET is quantified by considering human extrinsic (land cover, topography, population density) and intrinsic factors (age, gender distribution) by assigning different evacuation speeds properties and evacuation speed reductions derived from literature. Considered factors are substantiated by literature studies and findings from disaster aftermath exercises.

Spatially distributed ET is calculated on the basis of a cost distance weighted algorithm and on two credible emergency planning zones: tsunami warning and major warning levels. The time potentially needed to reach the next safe area is provided for each tsunami endangered location on land along the coast. Parameterisation of key factors is based on literature and partly own estimation. Attached uncertainty is quantified with a coefficient of variation of approximately $5 \%$ when considering incomplete knowledge in parameterisation which states a robust estimation of ET. Additionally uncertainty is low in high tsunami risk areas (along the coastline).
Quantification of RsT is contextualized as different time compartments related to the warning chain (decision time, notification time, reaction time) and is essentially determined by the estimated time of tsunami arrival (ETA). Major unknown in RsT is the quantification of human reaction time (RT). Human reaction time is influenced by complex social, cultural and psychological factors which have to be substantiated by household surveys and community-based participatory methods. Based on nation wide available statistical data some known influencing factors (e.g. education, access to information) can be represented allowing a qualitative statement (e.g. good, moderate, weak human reaction capabilities) and make a robust quantitative statement difficult. Current research efforts try to solve this gap by characterizing RT at the local level using findings from conducted household surveys and participatory approaches.

Based on this the (optimal) human response capability was classified to weak, moderate and good. This information provides immediate judgement possibilities on where people are unable to rescue themselves on time and where a high vulnerability of people towards tsunamis exists. Presented results allow the detection of high vulnerability hotspots along the entire coast as well as on sub-district level.

Beside the quantified ETA, other time components making up response time are set to an optimal time because they are largely unknown. Consequently a dynamic representation of response time from optimum to minimum response time (constrained only by respective ETA values) is adopted. This allows for each warning segment and for different response time intervals a dynamic estimation of areas featuring weak response capabilities (response time shorter than necessary evacuation time). Summarizing the people located in the weak response zones per time interval leads to a representation of casualties as a function of time. For selected examples, a time dependent amount of casualties delivers key information on how severely a region might be impacted in terms of loss of live. A plausibility check based on reported dead/injured for Aceh tsunami 2004 hints to a robust estimation of casualties at the sub-national scale. The so provided information on casualties per response time available and for two tsunami intensity cases (tsunami warning levels) constitute new and key information in the frame of disaster management both at national and local level.

The overall assessment provides information up to subdistrict level (map scale up to 1:100 000). This allows decision makers at local level to identify hotspots of weak response capabilities and to evaluate estimated evacuation times related to expected tsunami arrival times. For identified hotspots and knowing the amount of people therein additional vertical evacuation shelters can be assigned or installed. Knowing the approximate number of casualties and dislocated people helps in planning evacuation shelter, basic need supply (food, water, medicine) and medical care capacity needed to cope with a tsunami disaster. Hence the information provided is an important contribution 
to evacuation and contingency planning. Additionally the integration of presented findings in community awareness and preparedness efforts helps to raise disaster knowledge and risk perception. People can learn about the approximate arrival times of potential tsunamis affecting their regions, what their potential evacuation time is and where tsunami safe areas are located. This might foster the urgent need of quick/direct tsunami response (evacuation action) at the local level. Highly important in terms of local level tsunami response is trust and believe in tsunami warnings and information issued by the warning centre. The link of warning information provided from the national level and the knowledge and implications of this information at the local level is crucial and needs continuous attention within disaster preparedness efforts. Tying national warning centre definitions (e.g. warning level information) to information and products derived from the presented work is seen to help understanding and to directly relate warning information to local disaster management implications.

At national level presented information can effectively be used to prioritize intervention mechanisms in terms of disaster risk reduction based on detected hotspots of weak human response capability. Additionally, using time dependent estimation of casualties the costs of late warnings (long institutional decision and notification time) or long human reaction times can be depicted clearly. For example an optimal early warning process and optimal human response would have reduced casualties significantly from reported 80000 to (estimated) approx. 19000 for a worst case tsunami (Banda Aceh, 2004 event). This tremendously points out the need and value of effective Early Warning Systems (minimizing institutional decision and notification times) and disaster risk reduction strategies (minimizing reaction and evacuation times) and the value of provided human response capability information.

Acknowledgements. This research work has been performed in the framework of the GITEWS (German Indonesian Tsunami Early Warning) project. The project is funded by the German Federal Ministry for Education and Research (BMBF), Grant 03TSU01. The authors are very thankful to all colleagues of the joint Indonesian - German working group on risk assessment and vulnerability modelling. Also the help of Achim Gössl and Sylvia Lex for data processing is acknowledged. Thanks to the reviewers for their valuable comments.

Edited by: J. Birkmann

Reviewed by: D. M. Herryal, N. Setiadi, and S. Leschka

\section{References}

ADPC: Evacuation routes tools ArcGIS toolbox - User's manual, Bangkok, 88, 2007.

Birkmann, J., Fernando, N., Hettige, S., Amarasinghe, S., Jayasingam, T., Paranagama, D., Nandana, M. D. A., Naßl, M., Voigt, S., Grote, U., Engel, S., Schraven, B., and Wolfertz,
J.: Rapid Vulnerability Assessment in Sri Lanka, UNU-EHS SOURCE No. 7, Bonn, 88, 2007.

Birkmann, J., Setiadi, N., and Gebert, N.: Sub national assessment of human vulnerability in the context of tsunami early warning, Nat. Hazards Earth Syst. Sci., in preparation, 2009.

Charnkol, T. and Tanaboriboon, Y.: Tsunami Evacuation behavior analysis, IATSS RESEARCH, 30, 83-96, 2006.

Cova, T. J. and Church, R. L.: Modelling community evacuation vulnerability using GIS, Int. J. Geogr. Inf. Sci., 11, 763-784, 1997.

Doocy, S., Gorokhovich, Y., Burnham, G., Balk, D., and Robinson, C.: Tsunami Mortality Estimates and Vulnerability Mapping in Aceh, Indonesia, American Journal of Public Health, 97, S146, 2007.

Drabek, T. E.: Understanding disaster warning responses, The Social Science Journal, 36, 515-523, 1999.

ESRI: ArcGIS (TM) Spatial Analyst: Advanced GIS Spatial Analysis Using Raster and Vector Data., ESRI White Paper, Redlands, 1-17, 2001.

Guha-Sapir, D. and Below, R.: The Quality and Accuracy of Disaster Data: A Comparative Analyses of Three Global Data Sets, World Bank, Disaster Management Facility, ProVention Consortium, Brussels, 18 pp., 2006.

Janssen, P. H. M., Heuberger, P. S. C., and Sanders, R.: UNCSAM: A tool for automating sensitivity and uncertainty analysis Environmental Software, 9, 1-11, 1994.

JICA: Study on the Urgent Rehabilitation and Reconstruction Plan for Banda Aceh City in the Republic of Indonesia, JICA, 2005.

Johnson, C. W.: Using Computer Simulations to Support A RiskBased Approach For Hospital Evacuation, 2006.

Kawamura, K., Tokuhiro, A., and Takechi, H.: Gait analysis of slope walking: a study on step length, stride width, time factors and deviation in the center of pressure, Acta Med. Okayama, 45, 179-184, 1991.

Klüpfel, H. L.: A Cellular Automaton Model for Crowd Movement and Egress Simulation, Ph.D., Universität Duisburg-Essen, 2003.

Klüpfel, H. L.: Modelle für die Berechnung von Personenströmen Evakuierungssimulationen., 2005.

Lindell, M. K. and Perry, R. W.: Behavioral foundations of community emergency planning, Hemisphere Pub., Washington, D.C., 1992.

MacDonald, R.: How Women Were Affected by the Tsunami: A Perspective from Oxfam, PLoS Medicine, 2, e178, 2005.

Mileti, D. S. and Sorensen, J. H.: Communication of emergency public warnings: A social science perspective and state-of-the-art assessment, ORNL-6609, Oak Ridge National Lab., TN (USA), 1990.

Mileti, D. S.: Factors related to flood warning response, US-Italy Research, 1995.

Oxfam: The Tsunami's impact on women, Oxfam Briefing Note, 30 March, 14, 2005.

Post, J., Hattermann, F. F., Krysanova, V., and Suckow, F.: Parameter and input data uncertainty estimation for the assessment of long-term soil organic carbon dynamics, Environmental Modelling and Software, 23, 125-138, 2008a.

Post, J., Zosseder, K., Wegscheider, S., Steinmetz, T., Riedlinger, T., Strunz, G., Mehl, H., Dech, S., Birkmann, J., Gebert, N., Anwar, H. Z., and Harjono, H.: Risk assessment to low frequency - high impact coastal hazard in Indonesia: Integrating 
tsunami hazard and vulnerability assessment in the context of Early Warning, International Conference on Tsunami Warning (ICTW), Bali, 2008-11-12-2008-11-14, 2008b.

Rofi, A., Doocy, S., and Robinson, C.: Tsunami mortality and displacement in Aceh province, Indonesia, Disasters, 30, 340-350, 2006.

Rogsch, C.: Vergleichende Untersuchungen zur dynamischen Simulation von Personenströmen, Forschungszentrum, Zentralbibliothek, 2005.

Saltelli, A., Tarantola, S., Campolongo, F., and Ratto, M.: Sensitivity Analysis in Practice: A Guide to Assessing Scientific Models John Wiley and Sons, Hoboken, NJ 232 pp., 2004.

Sorensen, J. H.: Warning systems and public warning response, United States, OSTI ID: 10191628; Legacy ID: DE93041049, Size: 15 p., 1993.

Sorensen, J. H.: Hazard Warning Systems: Review of 20 Years of Progress, Natural Hazards Review, 1, 119-125, 2000.

Sorensen, J. H., Shumpert, B. L., and Vogt, B. M.: Planning for protective action decision making: evacuate or shelter-in-place, Journal of Hazardous Materials, 109, 1-11, 2004.
Tarantola, S.: SimLab 2.2 Reference Manual. Institute for Systems, Informatics and Safety, European Commission, Joint Research Center, Ispra, Italy, 158 pp., 2005

Thompson, P.: Simulex: simulated people have needs too. NIST Workshop on Building Occupant Movement during Fire Emergencies, NIST, 1-10, 2004.

Toyosawa, Y. and Horii, N.: Specific Research on Preventional Countermeasures of Labor Accidents due to Debris Flow. 4. Evaluation of Evacuation Time from Debris Flow by On-site Experiments, Specific Research Reports of the National Institute of Industrial Safety, 25-37, 2002.

UN/ISDR PPEW: www.unisdr.org/ppew/whats-ew/basics-ew.htm, accessed at 18 June 2009

Verbeeck, H., Samson, R., Verdonck, F., and Lemeur, R.: Parameter sensitivity and uncertainty of the forest carbon flux model FORUG: a Monte Carlo analysis, Tree Physiol, 26, 807-817, 2006.

Wang, J.-F. and Lian, F. L.: Improving Tsunami warning Systems with remote sensing and geographical information system input, Risk analysis, 28, 1653-1668, 2008. 